Document downloaded from:

http://hdl.handle.net/10251/33015

This paper must be cited as:

Robles Martínez, A.; Durán Pinzón, F.; Ruano García, MV.; Ribes Bertomeu, J.; Ferrer Polo, J. (2012). Influence of total solids concentration on membrane permeability in a submerged hollow-fibre anaerobic membrane bioreactor. Water Science and Technology. 66(2):377-384. doi:10.2166/wst.2012.196.

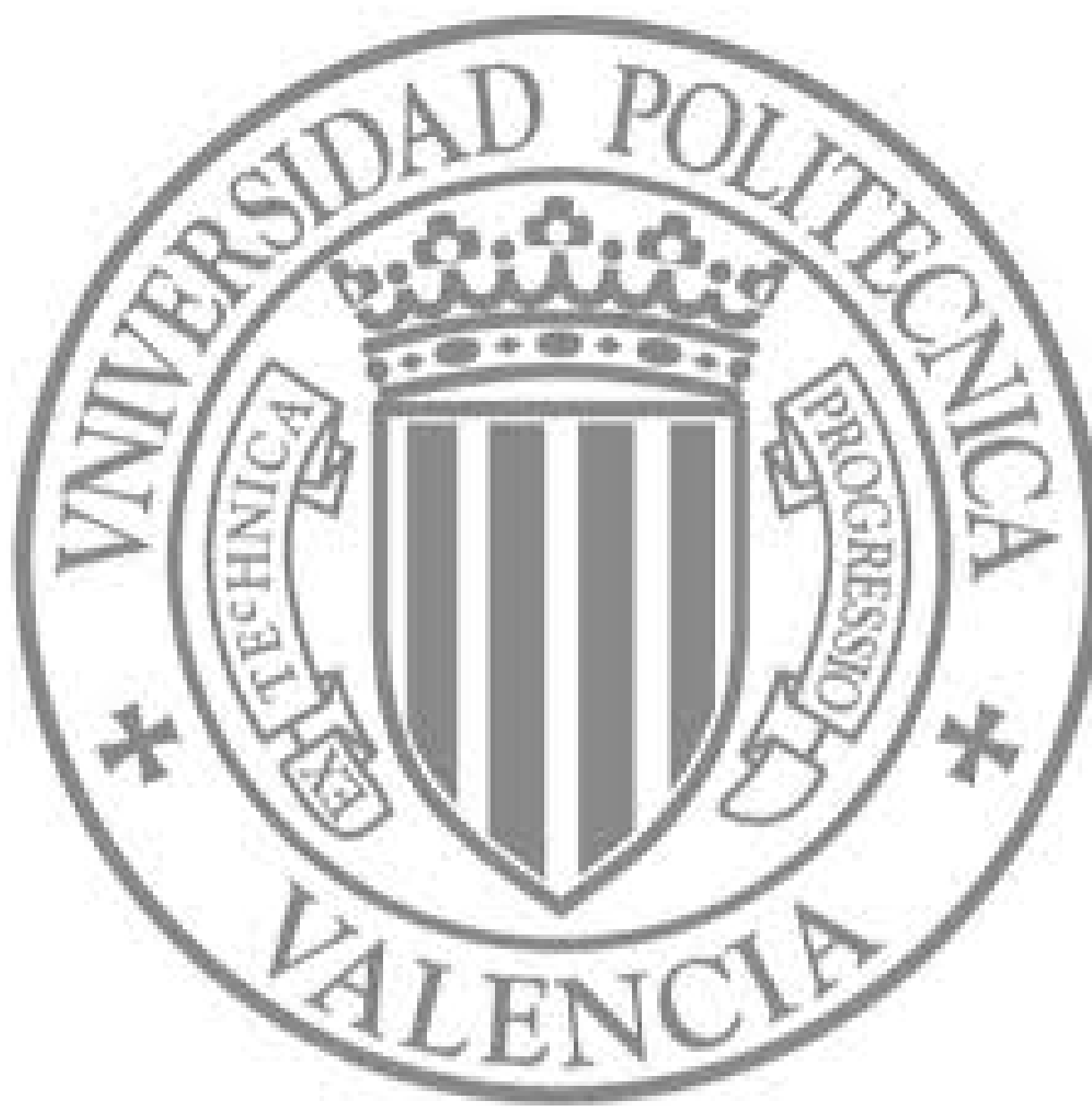

The final publication is available at

http://www.iwaponline.com/wst/06602/wst066020377.htm

Copyright IWA Publishing 


\title{
Influence of total solids concentration on membrane permeability in a submerged hollow-fibre anaerobic membrane bioreactor
}

\author{
A. Robles*, F. Durán*, M.V. Ruano**, J. Ribes** and J. Ferrer* \\ * Instituto de Ingeniería del Agua y Medio Ambiente. Universitat Politècnica de València. Camí de Vera \\ s/n. 46022. València. Spain. \\ (E-mail: ngerobma@upvnet.upv.es; fredurpi@upvnet.upv.es; jferrer@hma.upv.es) \\ ** Dep. Ingeniería Química. Universitat de València. Dr Moliner, 50. 46100. Burjassot. València. Spain. \\ (E-mail: m.victoria.ruano@uv.es; josep.ribes@uv.es)
}

\begin{abstract}
The main aim of this work was to study the influence of the Mixed Liquor Total Solids (MLTS) concentration on membrane permeability $\left(\mathrm{K}_{20}\right)$ in a Submerged Anaerobic Membrane Bioreactor (SAnMBR) pilot plant, which is equipped with industrial hollow-fibre membranes and treats urban wastewater. This pilot plant was operated at $33{ }^{\circ} \mathrm{C}$ and 70 days of SRT. Two different transmembrane fluxes (13.3 and $10 \mathrm{LMH}$ ) were tested with a gas sparging intensity of $0.23 \mathrm{Nm}^{3}$ $\mathrm{m}^{-2} \mathrm{~h}^{-1}$ (measured as Specific Gas Demand referred to membrane area). A linear dependence of $\mathrm{K}_{20}$ on MLTS concentration was observed within a range of MLTS concentration from 13 to $32 \mathrm{~g} \mathrm{~L}^{-1}$ and $\mathbf{J}_{20}$ of $10 \mathrm{LMH} . \mathrm{K}_{20}$ maintained at sustainable values (about $100 \mathrm{LMH} \mathrm{bar}^{-1}$ ) even at high MLTS concentrations (up to $20 \mathrm{~g} \mathrm{~L}^{-1}$ ). In addition, several short-tests were carried out when the membranes were operated at high MLTS concentrations in order to assess the effect of the physical cleaning strategies (relaxation and back-flush) on membrane performance. It was observed that, with the applied gas sparging intensity, the duration of the relaxation stage did not critically affect the membrane performance. On the other hand, the required back-flush frequency was considerably affected by the MLTS concentration.
\end{abstract}

\section{Keywords}

Fouling rate; industrial membranes; mixed liquor total solids concentration; submerged anaerobic membrane bioreactor; permeability.

\section{INTRODUCTION}

In the latest years, membrane bioreactors (MBR) have been successfully implemented in a large number of wastewater treatment plants. Furthermore, this reliable and efficient technology has become a legitimate alternative to conventional activated sludge processes. This technology can no longer be considered as a novel process since it is already an option for urban wastewater treatment (Le-Chech el al., 2006). MBR technology presents as main advantages a complete physical retention of solids and almost all microorganisms, a high effluent quality and disinfection capability, and a small footprint (Judd, 2006). However, aerobic MBRs present the two main drawbacks of aerobic processes: the generation of large quantities of secondary sludge that requires treatment before re-use/cycle (Hughes et al., 2010), and the high energy requirements for the aeration process (up to the 50\% of the whole energy consumption of a conventional WWTP). Both high waste generation and high energy demand are against sustainability principles. In recent years there is an increasing interest in the study of anaerobic urban wastewater treatment at ambient temperature. This interest is focused on the sustainability benefits that anaerobic processes present compared to aerobic ones, such as: minimum sludge production due to the low biomass yield of anaerobic organisms; low energy demand since no aeration is required; biogas production that can be used to fulfil process energy requirements (Ho and Sung, 2010); and a negative balance of greenhouse gases emission, since most of the required energy comes from the wastewater instead of from fossil fuels. However, anaerobic processes present as main key issue the low growth-rates of anaerobic biomass at ambient temperature (Lin et al., 2010), which requires high solid retention times (SRT) in order to achieve proper organic matter removal rates. 
In this sense, the MBR technology can overcome the main limitations of anaerobic processes at low temperatures and loads: complete retention of slow-growth-rate microorganisms can be guaranteed (no washout of these microorganisms), and high SRT can be achieved with small volumes (no matter about settling problems). Furthermore, the membrane separation process allows high organic loading to be obtained with urban wastewater, since low COD concentrations are remedied by high treatment flow rates in small reaction volumes: something not possible with classical anaerobic systems (UASB and EGSB) due to the limitations of gravity-based separation processes. Thus, anaerobic membrane bioreactors (AnMBR) are a promising technology for urban wastewater treatment (Hu et al., 2006; Huang et al., 2008; Giménez et al., 2011).

However, working at high Mixed Liquor Total Solid (MLTS) concentrations is one of the main operating restrictions in filtration-based technology (Judd, 2006). These large MLTS concentrations favour membrane fouling, which decreases membrane permeability $(\mathrm{K})$ and increases operating and maintenance costs (Chang et al., 2002). In this respect, the effect of the MLTS concentration on membrane performance must be studied in order to assess AnMBR feasibility to treat urban wastewater. It is important to emphasise that AnMBR systems enable membranes to operate at MLTS concentrations higher than those achieved in aerobic MBRs because anaerobic MBRs do not present the oxygen transfer constraints that limit MLTS concentrations in aerobic MBRs (Stephenson et al., 2000). Hence, a considerable reduction in the design operating volume can be achieved in comparison with the volume required in aerobic conditions.

In order to minimise membrane fouling, as well as to increase the membrane lifespan, the optimisation of membrane operation and configuration becomes the main operating challenge for AnMBR. With regard to membrane operation, the main variables to be optimised are: the frequency and duration of the physical cleaning stages (relaxation or back-flush), the crossflow sludge velocity, and the gas sparging intensity in the membrane tank. Moreover, membrane fouling can be reduced by means of operating membranes at sub-critical filtration conditions, which are bounded by the so-called critical flux $\left(\mathrm{J}_{\mathrm{C}}\right)$, firstly defined as "the flux below which no fouling occurs" (Bachin et al., 1995), or as "the flux below which a decline of flux with time does not occur; above it, fouling is observed" (Field et al., 1995). Concerning membrane configuration, the implementation of hollow-fibre (HF) membranes in the so-called submerged anaerobic membrane bioreactor (SAnMBR) seems to be one of the most feasible configurations to treat large wastewater volumes. Compared to cross-flow membranes, HF membranes present low energy consumption since they are located directly in the mixed liquor and the required energy gap for the vacuum filtration process is reduced. This configuration facilitates the recycle of the produced biogas to the membrane tank for insitu gas sparging (Lin et al., 2010), which reduces the cake layer formation-rate. Hence, AnMBR for treating urban wastewater can take advantage of the long experience on $\mathrm{HF}$ membranes in aerobic MBR plants.

Several studies have been published where the feasibility of SAnMBR technology has been demonstrated. Most of these studies have been assessed at laboratory scale plants (Hu and Stuckey, 2006; Fawehinmi et al., 2007), with flat sheet or tubular membranes (Jeison and Van Lier, 2006; Lin et al., 2009), or treating synthetic wastewater (Huang et al., 2008; Ho and Sung, 2010). Nevertheless, fewer references have been found in the literature concerning the assessment of HF membranes performance at anaerobic conditions. Its feasibility has been mainly assessed at aerobic conditions (see v.g. Guglielmi et al., 2006, 2007). Moreover, no references have been found regarding HF-SAnMBR application at semi-industrial scale treating urban wastewater. In this sense, since the membrane performance cannot be directly 
scaled-up from laboratory to real plant, especially with HF-based technology, further studies at industrial-scale are needed in order to facilitate the design and implementation of this technology at full-scale WWTPs.

To gain more insight into the optimisation of the physical separation process in a SAnMBR system on an industrial scale, the effect of the main operating variables on industrial HF membranes performance was evaluated in this work. The main objective was to assess the effect of MLTS concentration on membrane permeability. Furthermore, the effect of duration and frequency of the physical cleaning stages (relaxation and back-flush) on membrane performance was studied whilst operating the membranes at high MLTS concentrations. In order to obtain robust results that can be extrapolated to full-scale plants, a SAnMBR system featuring industrial HF membrane units was operated using effluent from the pre-treatment of the Carraixet WWTP (Valencia, Spain).

\section{MATERIAL AND METHODS}

\section{Experimental set-up and operation}

The semi-industrial SAnMBR pilot plant (see Figure 1a) was designed to treat a maximum flow-rate of $1200 \mathrm{~L} \mathrm{~h}^{-1}$, assuming a net flux of $20 \mathrm{~L} \mathrm{~m}^{-2} \mathrm{~h}^{-1}$ in both membrane tanks. It consists of an anaerobic reactor of $1.3 \mathrm{~m}^{3}$ total volume $\left(0.4 \mathrm{~m}^{3}\right.$ head-space volume $)$ connected to two membrane tanks of $0.8 \mathrm{~m}^{3}$ total volume each $\left(0.2 \mathrm{~m}^{3}\right.$ head-space volume $)$. Each membrane tank includes one commercial hollow-fibre ultrafiltration membrane module (PURON®, Koch Membrane Systems, $0.05 \mu \mathrm{m}$ pore size). Each module consists of 9 hollowfibre bundles of $1.8 \mathrm{~m}$ length that give a total of $30 \mathrm{~m}^{2}$ membrane surface. A rotofilter of 0.5 $\mathrm{mm}$ screen size has been installed as pre-treatment system in order to minimise clogging problems. One equalization tank $\left(0.3 \mathrm{~m}^{3}\right)$ and one Clean-In-Place (CIP) tank $\left(0.2 \mathrm{~m}^{3}\right)$ are also included as main elements of the pilot plant. In order to control the temperature when necessary, the anaerobic reactor is jacketed and connected to a water heating/cooling system.

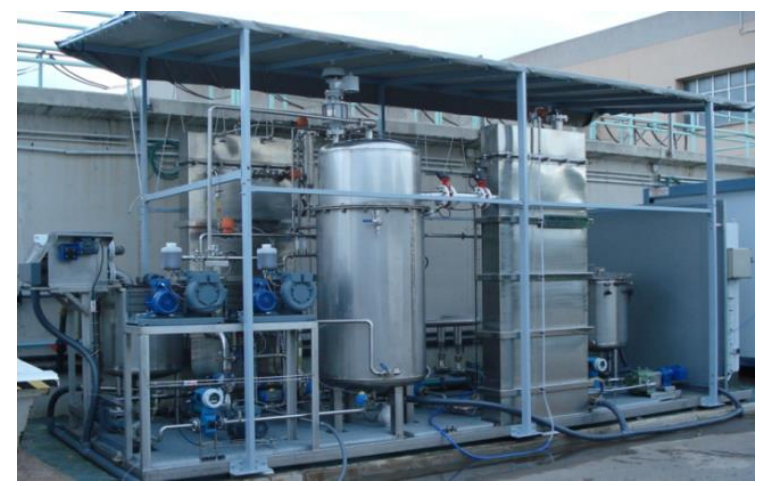

(a)

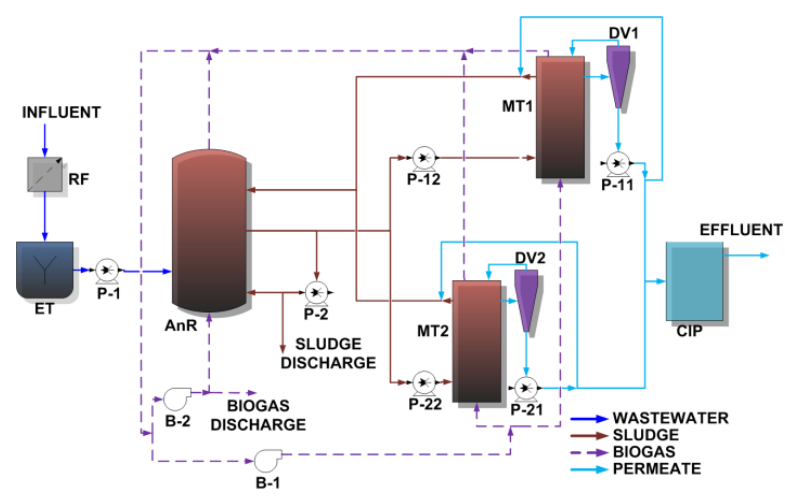

(b)

Figure 1. General view of (a) the pilot plant and (b) the flow diagram. (Nomenclature: RF: rotofilter; ET: equalization tank; AnR: anaerobic reactor; MT: membrane tanks; DV: degasification vessel; CIP: clean-in-place; P: pump; and B: blower).

Figure $1 \mathrm{~b}$ shows the flow diagram of the pilot plant. The pilot plant is fed with the effluent of the Carraixet WWTP pre-treatment, which consists of screening, degritter, and grease removal. After further pre-treatment in the rotofilter (RF) and homogenisation in the equalization tank (ET), the wastewater is pumped to the anaerobic reactor (AnR). In order to improve the stirring conditions of the anaerobic reactor and to favour the stripping of the produced gasses from the liquid phase, a fraction of the produced biogas is recycled to this 
reactor. The sludge is continuously recycled through the external membrane tanks (MT) where the effluent is obtained by vacuum filtration. In order to minimise the cake layer formation, another fraction of the produced biogas is also recycled to the membrane tanks from the bottom of each fibre bundle. With the aim of recovering the biogas bubbles extracted with the membrane effluent, a degasification vessel (DV) was installed between the MT and the vacuum pump. This DV consists of a conic-shaped pipe-section widening that favours the biogas accumulation at the top of this element. The obtained permeate is stored in the CIP tank. By using two membrane tanks in parallel, the pilot plant has been designed and automated with high operating flexibility, which allows the pilot plant to work with either one membrane tank or both tanks. In addition, an internal permeate recycle has been installed in both membrane tanks in order to allow decoupling both physical process and biological process study. Hence, different transmembrane fluxes can be tested without affecting the hydraulic retention time (HRT) of the plant. In order to control the solids retention time (SRT) in the system, a fraction of the sludge is intermittently extracted from the anaerobic reactor throughout the day. The treatment flow-rate is established by the selected membrane operating mode. Every membrane operating mode is carried out by a defined schedule of different individual stages that are combined from a filtration-relaxation (F-R) basic cycle (see Figure 2). Besides classical membrane operating stages (filtration, relaxation, and back-flush), two additional stages were also considered in the membrane operation (degasification and ventilation stages, see Durán et al. (2010)).

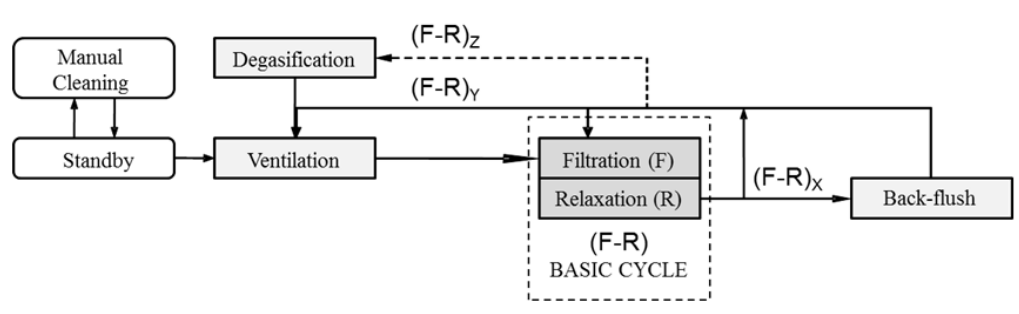

Figure 2. Operating mode flow diagram.

The SAnMBR pilot plant was operated at SRT of 70 days and controlled temperature of 33 ${ }^{\circ} \mathrm{C}$. During the experimental period, membranes were operated at two different $20{ }^{\circ} \mathrm{C}$ normalised transmembrane fluxes $\left(\mathrm{J}_{20}\right), 13.3 \mathrm{LMH}$ and $10 \mathrm{LMH}$. The membrane operating mode was established as follows: F-R basic cycles of 300 seconds in length $(250 \mathrm{~s}$ filtration and 50 s relaxation); 30 seconds of back-flush every 10 F-R basic cycles; 30 seconds of ventilation every $10 \mathrm{~F}-\mathrm{R}$ basic cycles; and 30 seconds of degasification every $50 \mathrm{~F}-\mathrm{R}$ basic cycles. The effect of physical cleaning stages (duration of the relaxation stage and back-flush frequency) on $\mathrm{K}_{20}$ was assessed by performing several short-term tests at different MLTS concentrations. The specific gas demand referred to membrane area ( $\left.\mathrm{SGD}_{\mathrm{m}}\right)$ was set to 0.23 $\mathrm{Nm}^{3} \mathrm{~m}^{-2} \mathrm{~h}^{-1}$ (overall recycled biogas flow-rate of $7 \mathrm{Nm}^{3} \mathrm{~h}^{-1}$ ).

\section{Instrumentation, control and automation system description}

In order to obtain on-line information about the state of the process for proper control performance, numerous on-line sensors and automatic equipment have been installed. The instrumentation is connected to a network system which includes several transmitters, a Programmable Logic Controller (PLC) and a PC to perform multi-parameter control and data acquisition. Both, data logging and pilot plant control, are carried out by a SCADA system installed in the PC, which centralises all the signals from the different sensors and the automatic equipment that are installed in the plant. The group of on-line sensors associated to each membrane tank consists of the following: $1 \mathrm{pH}$-Temperature transmitter (Endress Hauser, Orbisint CPS11D Memosens); 1 level indicator transmitter (Endress Hauser, Waterpilot FMX167); 1 flow indicator transmitter for the mixed liquor fed pump (Endress 
Hauser, Promag 50W); 1 flow indicator transmitter for the permeate pump (Endress Hauser, Promag 50P); and a liquid pressure indicator transmitter in order to control the TMP (Endress Hauser, Cerabar M PMC41). In addition, the pilot plant is equipped with several automatic actuators used for control purposes. The group of actuators associated to each membrane tank consists of a group of on-off control valves, which are used to establish the flow direction aimed to control the different membrane operation stages (filtration, back-flush, relaxation...), and 3 frequency converters (Micromaster Siemens 420). Each frequency converter commands the rotational speed of the permeate pump (JUROP VL02 NBR), the mixed liquor fed pump (CompAir NEMO), and the blower (FPZ 30HD) associated to each membrane tank.

\section{Pilot plant monitoring and membrane performance analysis}

Pilot plant performance is evaluated through the available on-line information and the analytical monitoring of the main process parameters. Samples of influent, mixed sludge, and effluent were taken periodically from the system. Most of the basic analytical techniques, including MLTS, were carried out in accordance with Standard Methods (APHA, 2005).

The $20^{\circ} \mathrm{C}$-normalised membrane permeability $\left(\mathrm{K}_{20}\right)$ was calculated using a simple filtration model (Eq. 1) that takes into account the on-line monitored data of TMP and J. This simple filtration model includes temperature (T) correction (Eq. 2) to account for the dependence of permeate viscosity $(\eta)$ on temperature (Rosenberger et al., 2006), and therefore $J_{20}$ was obtained by using Eq. 3. The total membrane resistance $\left(\mathrm{R}_{\mathrm{T}}\right)$ was supposed to be represented by the following partial resistances (Eq. 4): membrane resistance $\left(\mathrm{R}_{\mathrm{M}}\right)$; cake layer resistance $\left(\mathrm{R}_{\mathrm{C}}\right)$; and irreversible layer resistance $\left(\mathrm{R}_{\mathrm{I}}\right)$. Fouling rate was calculated using a classical regression model (Eq. 5) that takes into account the total number of monitored data (n) during.

$$
\begin{aligned}
& K_{20}=\frac{1}{\eta \cdot R_{T}}=\frac{J_{T} f_{T}}{T M P} \\
& f_{T}=e^{-0.0239(T-20)} \\
& J_{20}=J_{T} \cdot e^{-0.0239(T-20)} \\
& R_{T}=R_{M}+R_{C}+R_{I} \\
& \frac{d T M P}{d t}=\frac{n \cdot \sum_{1}^{n}\left(T M P_{i} \cdot t_{i}\right)+\sum_{1}^{n} T M P_{i} \cdot \sum_{1}^{n} t_{i}}{n \cdot \sum_{1}^{n} T M P_{i}^{2}-\left(\sum_{1}^{n} T M P_{i}\right)^{2}}
\end{aligned}
$$

\section{RESULTS AND DISCUSSIONS}

\section{Long-term test: influence of MLTS concentration on membrane performance}

Figure 3a shows the $\mathrm{K}_{20}$ profile obtained during the whole experimental period, as well as the MLTS concentration in the anaerobic sludge fed to the membrane tank. Important to highlight is that this concentration increased in the membrane tank according to the ratio between the sludge flow-rate fed to the membrane tank and the net permeate flow-rate. This figure shows a high influence of the MLTS concentration on $K_{20}$ for the two series carried out at different $\mathbf{J}_{20}$. Every MLTS concentration variation was inversely reflected on $\mathrm{K}_{20}$. Nevertheless, even for high MLTS concentrations (up to $23 \mathrm{~g} \mathrm{~L}^{-1}$ ) the $\mathrm{K}_{20}$ maintained at sustainable values. As can be observed in this Figure, for a $\mathrm{J}_{20}$ of $10 \mathrm{LMH}$ the $\mathrm{K}_{20}$ maintained above $100 \mathrm{LMH} \mathrm{bar}^{-1}$ until the MLTS raised a concentration around $25 \mathrm{~g} \mathrm{~L}^{-1}$. Figure 3a shows how for an almost stable MLTS concentration (see period from days 90 to 110 or period from days 120 to 135 ), $\mathrm{K}_{20}$ was quite stable. The stability in $\mathrm{K}_{20}$ could be attributed to the low TMP obtained during this period, which minimises membrane compression thus giving a stable $\mathrm{R}_{M}$ value. Moreover, 
following studies showed that $\mathrm{K}_{20}$ came back to previous values when the MLTS decreased (data not shown), which indicates the absence of irreversible fouling over the membrane surface (related to $\mathrm{R}_{\mathrm{I}}$ ). Hence, the higher $\mathrm{K}_{20}$ obtained during the initial months of operation was related to a lower cake layer formation-rate due to lower MLTS concentrations. Important to highlight is that there are two different effects that determine $\mathrm{R}_{\mathrm{C}}$ : the cake layer formationrate (due to the filtration process) and the cake layer removal-rate (mainly due to the biogas sparging). It is a well-known fact that for an established $\mathrm{SGD}_{\mathrm{m}}$ the cake layer removalefficiency decreases when the MLTS concentration increases. Therefore, in this work the decrease of the $\mathrm{K}_{20}$ due to increasing the MLTS concentration was mainly related to an increase in the $\mathrm{R}_{\mathrm{C}}$.

A linear dependence of the $\mathrm{K}_{20}$ on the MLTS concentration can be observed in Figure $3 \mathrm{~b}$ for the two series carried out at different $\mathbf{J}_{20}$. As can be observed in this Figure, any increase in the MLTS concentration results in a proportional decrease of the $K_{20}$. Despite no clear differences were observed between both series, for similar MLTS concentration the higher the applied flux, the lower the obtained $\mathrm{K}_{20}$. This little difference can also be observed in the slope of the linear regression between the MLTS concentration and the $\mathrm{K}_{20}$. This slope was slightly higher for $\mathrm{J}_{20}=13.3 \mathrm{LMH}$ than for $10 \mathrm{LMH}$, which indicates a higher fouling rate at higher fluxes. Moreover, both slopes seem to indicate that the influence of MLTS concentration on $\mathrm{K}_{20}$ starts getting independent on flux when the MLTS concentration tends to zero. This approach is in good agreement with the classical definition of membrane permeability treating pure water. On the contrary, while working at $\mathbf{J}_{20}=10 \mathrm{LMH}$, the MLTS concentration became one of the main factors affecting $\mathrm{K}_{20}$ when it suddenly increased above $30 \mathrm{~g} \mathrm{~L}^{-1}$.

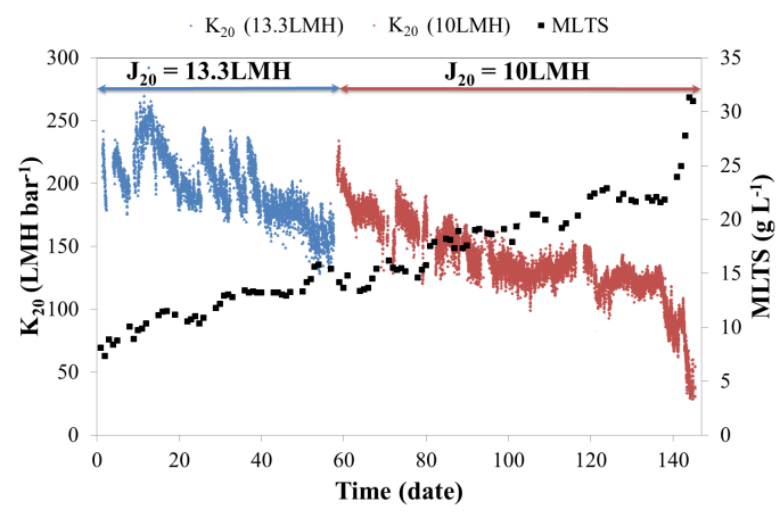

(a)

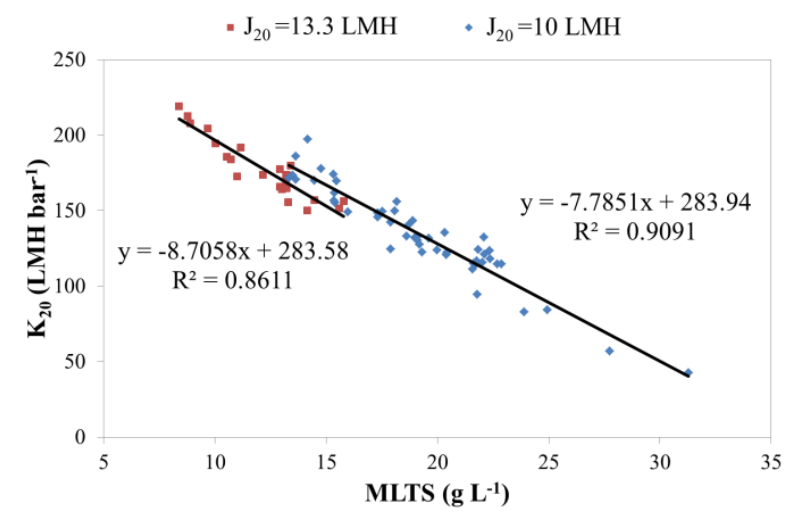

(b)

Figure 3. (a) Evolution of the $\mathrm{K}_{20}$ and the MLTS concentration throughout the experimental period. (b) Linear dependence of $\mathrm{K}_{20}$ on the MLTS concentration for the two series carried out at different $\mathbf{J}_{20}$.

Similar to Figure 3a, the MLTS concentration and the fouling rate are shown in Figure 4. As can be observed in this figure, the fouling rate maintained at low values until the MLTS concentration was around $25 \mathrm{~g} \mathrm{~L}^{-1}$. Above this value, the fouling rate showed a sudden increase due to the exceeding of the critical filtration conditions. For a $\mathrm{SGD}_{\mathrm{m}}$ of $0.23 \mathrm{Nm}^{3} \mathrm{~h}^{-1}$ $\mathrm{m}^{-2}$ and MLTS of $28 \mathrm{~g} \mathrm{~L}^{-1}$, the $20^{\circ} \mathrm{C}$-normalised critical flux was around $10 \mathrm{LMH}$, whilst for the same SGD $_{\mathrm{m}}$ and MLTS of $23 \mathrm{~g} \mathrm{~L}^{-1}$ it was around $13 \mathrm{LMH}$. The fouling rate presented in this Figure shows that filtration process was kept at sub-critical conditions until day 135 . Afterwards, the $\mathrm{SGD}_{\mathrm{m}}$ applied to the membrane tank was not enough to maintain sub-critical filtration conditions because of the high MLTS concentrations reached. However, as can be observed in Figure 4 it was possible to operate the membranes at low fouling rates at high 
MLTS concentrations (up to $23 \mathrm{~g} \mathrm{~L}^{-1}$ ).

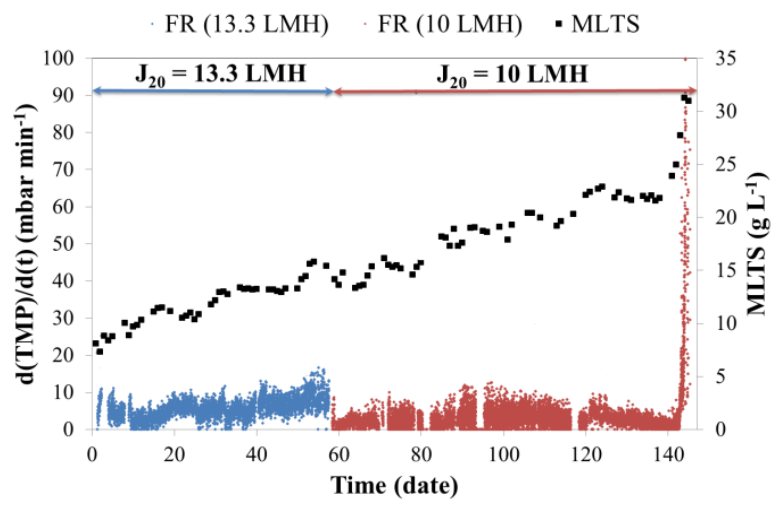

Figure 4. Evolution of the fouling rate (FR) and the MLTS concentration throughout the experimental period.

With regard to the biological process performance, Table 1 shows the average characteristics of influent and effluent SAnMBR streams. This table highlights the relatively low influent COD concentration, as well as the strong variability of the influent load as can be deduced from the high values of standard deviation associated to each parameter. The uncertainty associated to each value includes both the standard deviation of the different samples analysed throughout the experimental period and the coefficient of variation associated to the analytical methods. As can be observed, low effluent COD and VFA concentrations were achieved.

Overall, high treatment efficiency was obtained and no irreversible fouling problems were detected, and therefore, no chemical cleaning was conducted. Further details on the biological process performance of this SAnMBR system can be found in Giménez et al. (2011).

Table 1. Average characteristics of influent and effluent SAnMBR streams.

\begin{tabular}{llcc}
\hline Parameter & Unit & $\begin{array}{c}\text { Influent } \\
\text { Mean } \pm \text { SD }\end{array}$ & $\begin{array}{c}\text { Effluent } \\
\text { Mean } \pm \text { SD }\end{array}$ \\
\hline TSS & $\mathrm{mgTSS} \mathrm{L}^{-1}$ & $186 \pm 61$ & $<1$ \\
VSS & $\mathrm{mgVSS} \mathrm{L}^{-1}$ & $150 \pm 54$ & $<1$ \\
Total COD & $\mathrm{mgCOD} \mathrm{L}^{-1}$ & $445 \pm 95$ & $77 \pm 33$ \\
Soluble COD & $\mathrm{mgCOD} \mathrm{L}^{-1}$ & $73 \pm 25$ & $77 \pm 33$ \\
VFA & $\mathrm{mgCOD} \mathrm{L}^{-1}$ & $11 \pm 7$ & $12 \pm 7$ \\
$\mathrm{NH}_{4}-\mathrm{N}$ & $\mathrm{mgN} \mathrm{L}^{-1}$ & $27.0 \pm 8.1$ & $33.4 \pm 8.2$ \\
$\mathrm{PO}_{4}-\mathrm{P}$ & $\mathrm{mgP} \mathrm{L}^{-1}$ & $2.7 \pm 0.9$ & $3.1 \pm 0.9$ \\
Alkalinity & $\mathrm{mgCaCO}_{3} \mathrm{~L}^{-1}$ & $292.5 \pm 37.2$ & $596.5 \pm 65.6$ \\
\hline
\end{tabular}

Short-term tests: effect of the physical cleaning stages on membrane performance

With regard to the physical cleaning stages, several short-term tests were carried out in order to assess the influence of the relaxation stage duration and the back-flush application frequency on $\mathrm{K}_{20}$. Experiments for MLTS concentrations below $28 \mathrm{~g} \mathrm{~L}^{-1}, \mathrm{~J}_{20}$ of $10 \mathrm{LMH}$, and back-flush frequency of 1 back-flush every $10 \mathrm{~F}-\mathrm{R}$ cycles resulted in a total recovery of the $\mathrm{K}_{20}$ after the relaxation stage. Moreover, it was observed that the membrane performance was not critically affected by the duration of the relaxation stage when it was ranged between 30 and 60 seconds. On the other hand, Figure 5 shows the influence of the back-flush frequency on the TMP for different MLTS concentrations. This figure, which corresponds to a $\mathbf{J}_{20}$ of 10 LMH, shows how for MLTS below $26 \mathrm{~g} \mathrm{~L}^{-1}$ the TMP recovery did not depend on the back- 
flush frequency. Above this MLTS value, a significant increase of the TMP was observed, which made necessary to increase the back-flush frequency in order to keep the filtration process working below the safety threshold value (established at 0.4 bars). As can be observed in this figure, the safety threshold value was reached when membranes were operated at MLTS concentrations above $30 \mathrm{~g} \mathrm{~L}^{-1}$. However, as a result of the application of relaxation stages the membrane could be operated properly without a significant increase in the back-flush frequency.

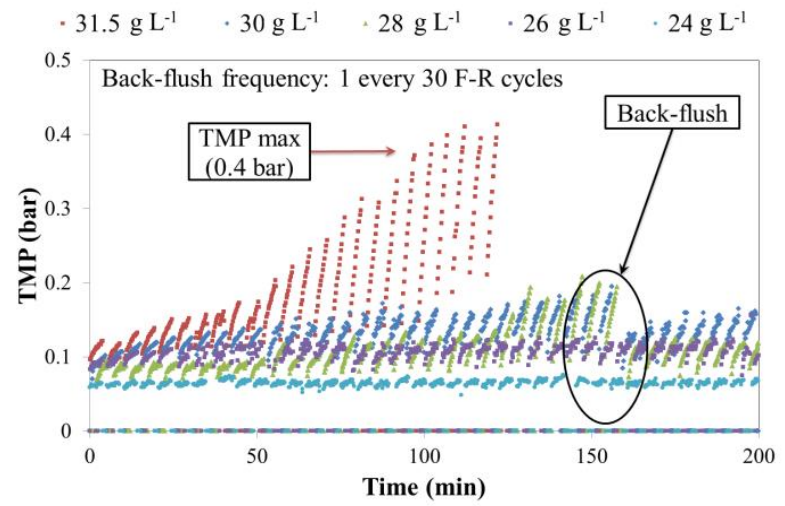

(a)

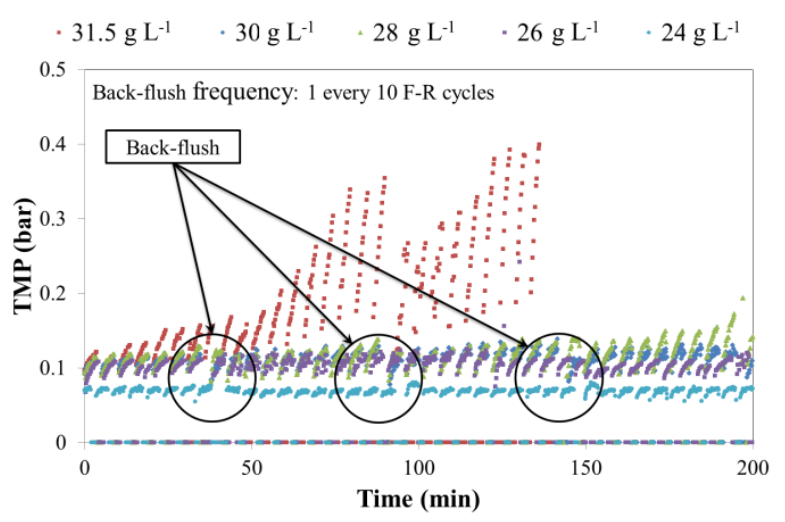

(b)

Figure 5. TMP evolution for different MLTS concentrations for a back-flush frequency of: (a) 1 back-flush every 30 F-R cycles; and (b) 1 back-flush every 10 F-R cycles.

As can be observed in Figure $5 \mathrm{~b}$, the membrane performance considerably improved due to increasing the back-flush frequency from 1 back-flush every 30 F-R cycles to 1 back-flush every $10 \mathrm{~F}-\mathrm{R}$ cycles. However, for MLTS concentrations above $30 \mathrm{~g} \mathrm{~L}^{-1}$ the TMP threshold value was still reached. As mentioned above, the MLTS concentration inside the membrane tank increased according to the ratio between the sludge flow-rate fed to the membrane tank and the net permeate flow-rate. For the established ratio, this concentration could have reached the value of $35 \mathrm{~g} \mathrm{~L}^{-1}$ when the MLTS concentration fed to the tank was $31 \mathrm{~g} \mathrm{~L}^{-1}$. The high fouling rate observed for both $31.5 \mathrm{~g} \mathrm{~L}^{-1}$ series was related to the increase predicted for the MLTS concentration in the membrane tank due to the mentioned ratio. For these

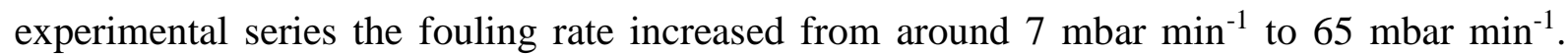
This increase throughout the experiment indicates that the MLTS limit which leads to operate the membranes above the critical filtration conditions were exceeded.

\section{CONCLUSIONS}

A SAnMBR pilot plant that includes industrial HF membranes was operated at mesophilic conditions (at $33^{\circ} \mathrm{C}$ ) and 70 days SRT with urban wastewater coming from the Carraixet WWTP (Valencia, Spain). The effect of the MLTS concentration on membrane fouling was assessed by operating the membranes at two different $\mathbf{J}_{20}: 13.3$ and $10 \mathrm{LMH}$. It was observed that the MLTS concentration highly affected the $\mathrm{K}_{20}$. However, the $\mathrm{K}_{20}$ maintained at sustainable values (over $100 \mathrm{LMH} \mathrm{bar}^{-1}$ ) even operating at high MLTS concentrations (up to $20 \mathrm{~g} \mathrm{~L}^{-1}$ ). The fouling rate maintained at low values and it only showed a sudden increase when the threshold value (about $25 \mathrm{~g} \mathrm{~L}^{-1}$ ) was exceeded. Moreover, a linear dependence between $\mathrm{K}_{20}$ and MLTS concentration was observed within a range of MLTS concentration from 13 to $32 \mathrm{~g} \mathrm{~L}^{-1}$ and $\mathrm{J}_{20}$ of $10 \mathrm{LMH}$, which predicts a proportional decrease in the $\mathrm{K}_{20}$ when the MLTS increases. Short-term tests showed that the duration of the relaxation stage did not critically affect the membrane performance. On the other hand, it was observed that the influence of the required back-flush frequency on membrane performance was strongly influenced by the MLTS concentration. 


\section{ACKNOWLEDGEMENT}

This research work has been supported by the Spanish Research Foundation (CICYT Projects CTM2008-06809-C02-01 and CTM2008-06809-C02-02), which is gratefully acknowledged.

\section{REFERENCES}

APHA (2005), Standard methods for the Examination of Water and Wastewater, $21^{\text {th }}$ edition. American Public Health Association/American Water Works Association/Water Environmental Federation, Washington DC, USA.

Bachin P., Aimar P., Sanchez V. (1995) Model for colloidal fouling of membranes. AIChE J. 41368 377.

Chang I. S., Clech P. L., Jefferson B. and Judd S. (2002) Membrane fouling in membrane bioreactors for wastewater treatment. J Environ Eng. 128 (11), 1018 - 1029.

Durán F., Carretero L., Giménez J.B., Robles A., Ruano M.V., Gatti M.N., Ribes J., Ferrer J. and Seco A. (2010) A Novel Pilot Plant for the Study of Submerged Anaerobic Membrane Bioreactor (SAMBR) Applied to Domestic Wastewater Treatment. Proceedings of the 12th World Congress on Anaerobic Digestion, IWA 4888, Guadalajara (Mexico), October 31st to November 4th, 2010.

Fawehinmi F., Jefferson B., Chan Tak and Rogalla F. (2007) Submerged Anaerobic Membrane Bioreactors (SAnMBR): Ready for the Big Ball? In: Proceedings of the Water Environment Federation, WEFTEC 2007, pp. 6393 - 6401(9).

Field R.W., Wu D., Howell J.A., Gupta B.B. (1995) Critical flux concept for microfiltration fouling. Journal of membrane science 100(3), 259 - 272.

Giménez J.B., Robles A., Carretero L., Durán F., Ruano M.V., Gatti M.N., Ribes J., Ferrer J. and Seco A. (2011) Experimental study of the anaerobic urban wastewater treatment in a submerged hollowfibre membrane bioreactor at pilot scale. Bioresour. Technol. 102(19), $8799-8806$.

Guglielmi G., Chiarani D., Judd S.J. and Andreottola G. (2006) Flux criticality and sustainability in a hollow fibre submerged membrane bioreactor for municipal wastewater treatment. J. Membr. Sci. 289(1-2), $241-248$.

Guglielmi G., Saroj D. P., Chiarani D. and Andreottola G. (2007) Sub-critical fouling in a membrane bioreactor for municipal wastewater treatment: Experimental investigation and mathematical modelling. Water Res. 41(17), 3903 - 3914.

Ho J. and Sung S. (2010). Methanogenic activities in anaerobic membrane bioreactors (AnMBR) treating synthetic municipal wastewater. Bioresour. Technol. 101, $2191-2196$.

Hu A.Y. and Stuckey D.C. (2006) Treatment of Dilute Wastewaters Using a Novel Submerged Anaerobic Membrane Bioreactor. J. Environ. Eng., 132 (2), 190 - 198.

Huang Z., Ong S.L. and Ng H.Y. (2008) Feasibility of submerged anaerobic membrane bioreactor (SAMBR) for treatment of low-strength wastewater. Wat. Sci. Tech. 58(10), $1925-1931$.

Hughes D., Kelly O., Collins G. and O'Flaherty V. (2010) Low temperature $\left(12^{\circ} \mathrm{C}\right)$ anaerobic treatment of sewage. Proceedings of the 12th World Congress on Anaerobic Digestion, IWA 4888, Guadalajara (Mexico), October 31st to November 4th, 2010.

Jeison D. and van Lier J.B. (2006) Cake layer formation in anaerobic submerged membrane bioreactors (AnSMBR) for wastewater treatment. J. Membr. Sci. 284(1-2), 227 - 236.

Judd S. (2006) The MBR Book: Principles and Applications of Membrane Bioreactors in Water and Wastewater Treatment (First Edition), ELVESIER.

Le-Clech P., Chen V. and Fane T. A.G. (2006) Fouling in membrane bioreactors used in wastewater treatment. J. Membr. Sci. 284(1-2), 17 - 53.

Lin H.J., Xie K., Mahendran B., Bagley D.M., Leung K.T., Liss S.N., Liao B.Q. (2009) Sludge properties and their effects on membrane fouling in submerged anaerobic membrane bioreactors (SAnMBRs). Water Res. 43 (15), 3827 - 3837.

Lin H.J., Xie K., Mahendran B., Bagley D.M., Leung K.T., Liss S.N., Liao B.Q. (2010) Factors affecting sludge cake formation in a submerged anaerobic membrane bioreactor. J. Membr. Sci. 361(12), $126-134$.

Rosenberger S., Laabs C., Lesjean B., Gnirss R., Amy G., Jekel M. and Schrotter J.C. (2006) Impact of colloidal and soluble organic material on membrane performance in membrane bioreactors for municipal wastewater treatment. Water Res. 40(4), 710 - 720. 
Stephenson, T., Judd, S., Jefferson, B., Brindle, K. (2000) Membrane Bioreactors for Wastewater Treatment. IWA publishing, London, UK. 